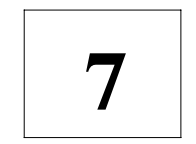

\title{
INTRODUCING TIME HORIZONS TO ENTERPRISE NETWORKING ARCHITECTURE
}

\author{
Nuno Álvares-Ribeiro ${ }^{1}$ \\ Ângelo Martins ${ }^{2}$ \\ João José Pinto Ferreira ${ }^{3}$ \\ ${ }^{1}$ FEUP-DEEC \\ ${ }^{2}$ DEI-ISEP \\ ${ }^{3}$ FEUP-DEEC/INESC Porto-UESP \\ nunoar@netcabo.pt,amartins@dei.isep.ipp.pt, jjpf@fe.up.pt
}

PORTUGAL

\begin{abstract}
Having in mind the inner value of the Zachman Framework for Enterprise Architecture itself, this paper explores the introduction of the time perspective into the framework by using GRAI-grid decision centres concept. The introduction to both these concepts paves the way to their combination in following paragraphs illustrating the Zachman / GRAI-grid conceptual integration for the analysis of a network of enterprises, finally illustrated with a case study.
\end{abstract}

\section{INTRODUCTION}

The Zachman Framework for Enterprise Architecture has been used in the understanding the enterprise architecture and organization dynamics. This framework was born in 1987, and since then it has suffered several changes and refinements in order to better cope with its objectives. The Zachman Framework for Enterprise Architecture is currently assembled as a matrix cross-combining enterprise aspects and perspectives. Despite its usefulness, the proposed Zachman matrix fails to implicitly model time, namely decisional time horizon's, critical whenever we want to look at both intra- and inter-enterprise operations.

Having in mind the inner value of the Zachman Framework for Enterprise Architecture itself, this paper explores the introduction of the time perspective into the framework. By introducing the modelling of decisional time horizons we aim to fostering the intra and inter-enterprise operations integration in enterprise networking. To this end, the authors start with an overview of the Zachman Framework, followed by a brief introduction to the GRAI-grid decision centres concept. The introduction to both these concepts paves the way to their combination 
in following paragraphs illustrating the Zachman / GRAI-grid conceptual integration for the analysis of a network of enterprises, finally illustrated with a case study.

\section{ZACHMAN FRAMEWORK FOR ENTERPRISE ARQUITECTURE}

Zachman Framework for Enterprise Architecture is a classification schema for organizing descriptive representations (artifacts). It can be a planning and a problem-solving tool. This schema has two dimensions that describe an enterprise. These dimensions contain six rows and six columns. Each one of the 6 rows represents six different perspectives: the planner, owner, designer, builder, subcontractor and the functioning enterprise. These rows intercept 6 columns that represent specific aspects, the what, how, where, who, when and why. When a row intercepts a column, there's a cell that represents a fundamental part of knowledge relation between the row and the column. This is known as primitive.

We would highlight Row 2, the one to be further analysed in this paper. Row 2 represents the Owner's perspective of the framework. The owner is often the intended recipient of the final product or service. The artifacts show what the owner is going to do with the product or service once it's in possession (O'Rourke, 2003). The owner's view is a conceptual view (business model) of the final product or service.

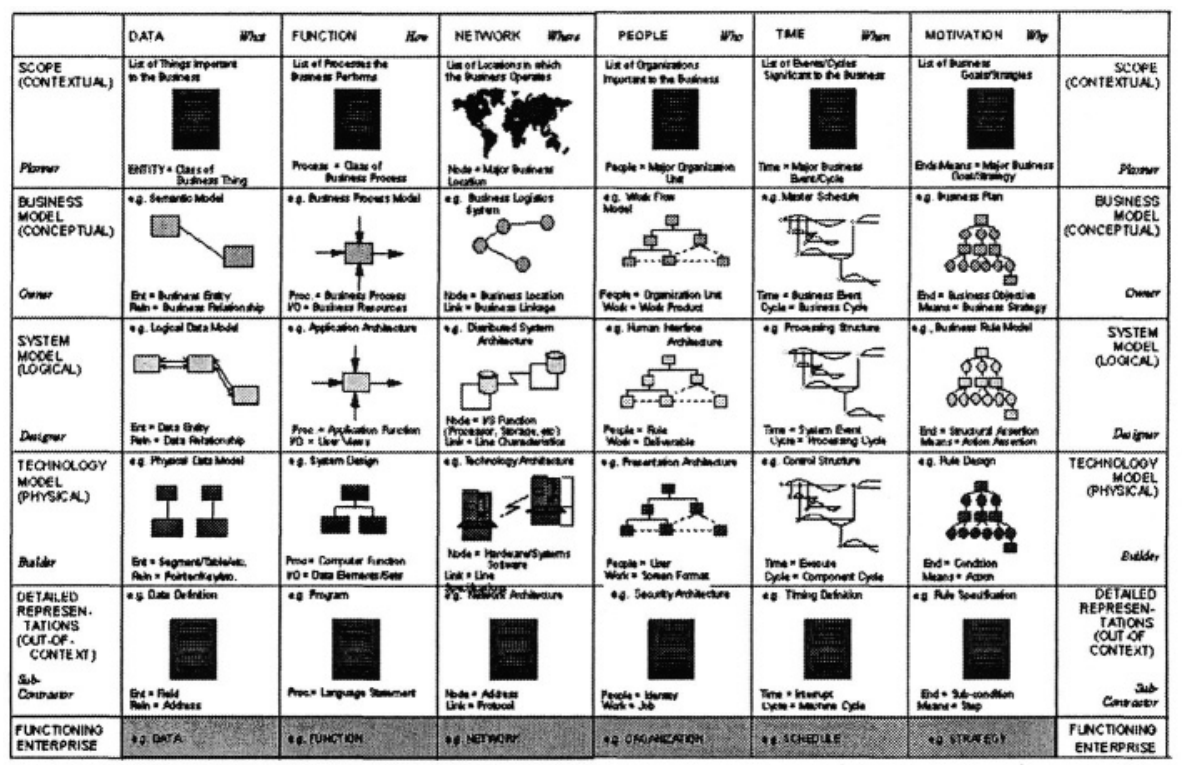

John A. Zachman, Zachman International

Figure 1 - Zachman Framework (O’Rourke, 2003)

An important matter to analyse is the implicit evolution that the aspects and perspectives have during different periods and horizons. For example, these periods/horizons can be represented in the Zachman Framework by replacing the When by several instances of the Framework as different plans (third axis) (Noran, 
2003). This new dimension is an orthogonal axis since the time is usually an independent aspect.

\section{GRAI-GRID}

The most popular GRAI Grid modeling language (Doumeingts et al, 1985) is used for modeling the decisional structure of the enterprise. The GRAI grid concept lies in the fact that any management decision that needs to be taken will always be made with reference to a horizon of time. Managers typically define strategic, tactical, operational and real-time management levels. These levels implicitly involve a hierarchy of decision functions structured as according to decision horizons (periods). The GRAI grid model further classifies functions of management distinguishing three functions: Product management; Resource management; and Co-ordination / planning. As an outcome of this approach, GRAI's goal is to give a generic description of manufacturing system focusing the system's control (production management, in broad sense). The manufacturing system control is treated, at the beginning, from a global point of view and later as a hierarchy of decision centres structured according to time horizon's.

\begin{tabular}{l|l|l|l} 
Horizon/Period & 1. Manage Products & 2. co-ordinate plan & 3. Manage Resources \\
\hline Strategic & & & \\
\hline Tactical & & & \\
\hline Operational & & & \\
\hline Real-time & & &
\end{tabular}

Figure 2 - Management function vs Decision horizont (Bernus P 1998)

The extension of this concept to the enterprise networking integration definitely claims for the business integration at all level of decisional hierarchy (Bernus $\mathrm{P}$ 1998) - Figure 3.

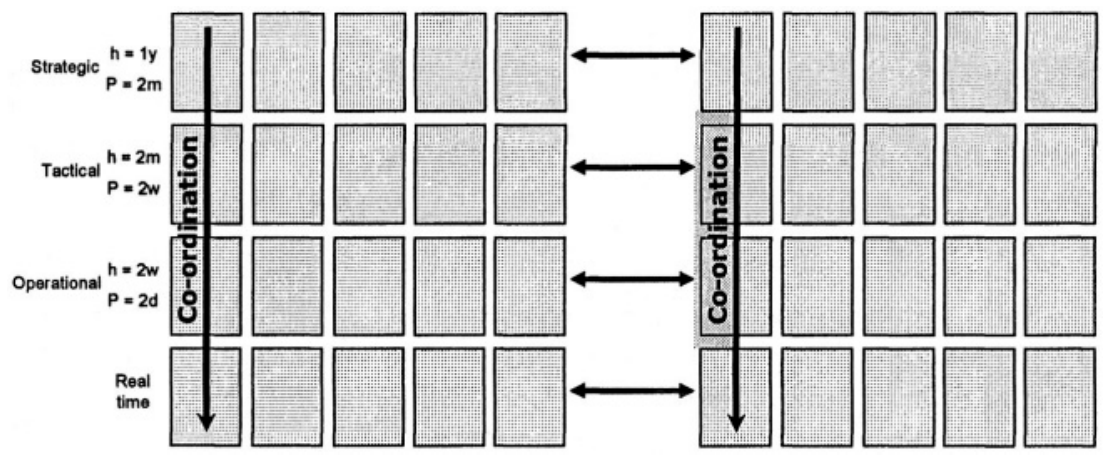

Figure 3 - Integrated Value Chain (Bernus P., 1998) 


\section{INTEGRATING THE TIME HORIZON IN THE ZACHMAN FRAMEWORK}

\subsection{Introduction}

As stated before, it was our objective to bring in time into the Zachman Framework in order to enable the adequate modeling of enterprise networking dynamics. To this end we looked into the Framework Row 2 (Owner) with the GRAI grid coordinate/plan view in order to extend the Zachman Framework into the four main decision horizons.

The authors took the business model perspective (coordinate/plan view) and introduced a third axis in order to cope with time.

The Strategic time horizon deals exclusively with general business concepts and definitions, namely the Where, When and Why aspects. General network structure and operating rules definition are a key aspect as, from the customer's viewpoint, the network of enterprises operates effectively as single entity. At this decision horizon, only key members will have a meaningful contribution, based on stable business relationships.

At the tactical horizon one is already dealing with the implementation of the business model (How and When). At this horizon the network structure is further refined to accommodate business particular requirements. Standardization is a mean to reach an end. It's valuable at a high level where it encourages the following goals: Reuse of Existing Assets; Integration of Efforts; Interoperability; Interchangeable Infrastructure.

Operational and real-time horizons finally deal with short term planning and scheduling, this respectively corresponding to the Zachman aspects Who/When and Where/Who/When.

\subsection{Case Study}

This case study is supported by the work developed in the course of MyFashion.eu European project (IST-2001-32560, http://www.myfashion.org). MyFashion.eu engages in the establishment of an innovative business model for customer configured apparel products made and delivered through a dynamically configured single-piece-flow supply network of manufacturers and service providers. The aim is to provide the consumer with extended and integrated fashion products (e.g. a suit, shirt, tie, belt and a pair of shoes) through the use of a workflow management information backbone and point-of-sale system that completely integrates the order and logistics processes. The traditional cascading apparel supply chain with its long lead times and its inflexible batch production is bypassed, thus giving regional, high quality EU textile and apparel manufacturers additional business opportunities.

The made-to-measure business model for the apparel industry tries to bridge the gap between the classic custom-made tailor products and the ready to wear massmarket concept, offering customized products at an affordable price. The population target is the affluent middle class and the sizable set of people (some estimates place it at $15 \%$ ) whose physical characteristics (e.g. arms' length) make it difficult or even impossible to buy cheaper ready to wear products. 
In the MyFashion business model, depicted in Figure 3, it is at the retailer's that most of the interaction with the customer takes place. The customer is presented with the possibility to self-configure its order, usually from a predefined set of choices, thus resulting in a one of a kind order that must be fulfilled by the enterprise network. Before placing an order, the customer at the retailer must be given the exact price and the scheduled delivery date of his order. Therefore, every member of the network must share some information about its manufacturing or processing capacity and, eventually, its own stocks of materials. This is not the kind of information enterprises usually like share with its costumers.

MyFashion business model can only be achieved through a real-time automated (or semi-automated) bidding and negotiation mechanism operating in a stable network of enterprises supported by a set of trust building services such as security management, quality control, etc. (Schiegg, 2003). Furthermore, every new collection (two to four each year, depending on the type of product) places specific requirements, thus resulting in a new/redesigned network configuration that will last up to the end of the season/collection.

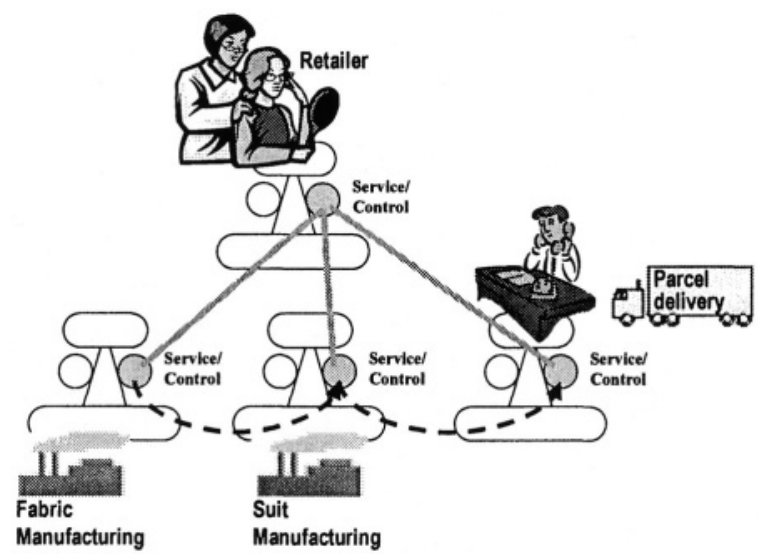

Figure 4 - MyFashion Business Model

Once the order is placed at the retailer, all network members cooperate to fulfill the order. The retailer's role may be just to monitor the order execution or may have an active role, for example supplying some materials or information to other members. As soon as the order is complete a parcel delivery company ships goods to the customer.

\subsection{Applying the combined Zachman / GRAI-Grid concept}

Figure 5 illustrates the outcome of this conceptualization effort introduced in paragraph 3.1, now applied to the MyFashion.eu case study. In this context the picture describes the network business model viewed along the typical four time horizons. This integrated view allows a comprehensive business analysis that is fulfilled by the connecting arrows. Doing now into a more detailed picture presentation we would have: 
- Strategic: strategic management levels deal with business concepts and definitions. In this case study one who look into the, general network structure (Where) and operating rules definition (When and Why). These are key aspects as the network of enterprises level. The made-to-measure model imposes further requirements at this level in the sense that when the costumer places an order at the retailer he must be given, in a mater of a very few minutes, the price and delivery time of his clothes. This is only possible if, and only if there is a seamless integration between all network members. Nevertheless, not all network members are equal, being some more important (leading) than others. At this horizon, only key leading members will have a meaningful contribution. In this context: arrow 1 depicts the strategic planning among network leading partners; arrow 2 sets a decisional frame for the tactical level; finally, arrow 8 sets the framework for the network dynamic configuration.

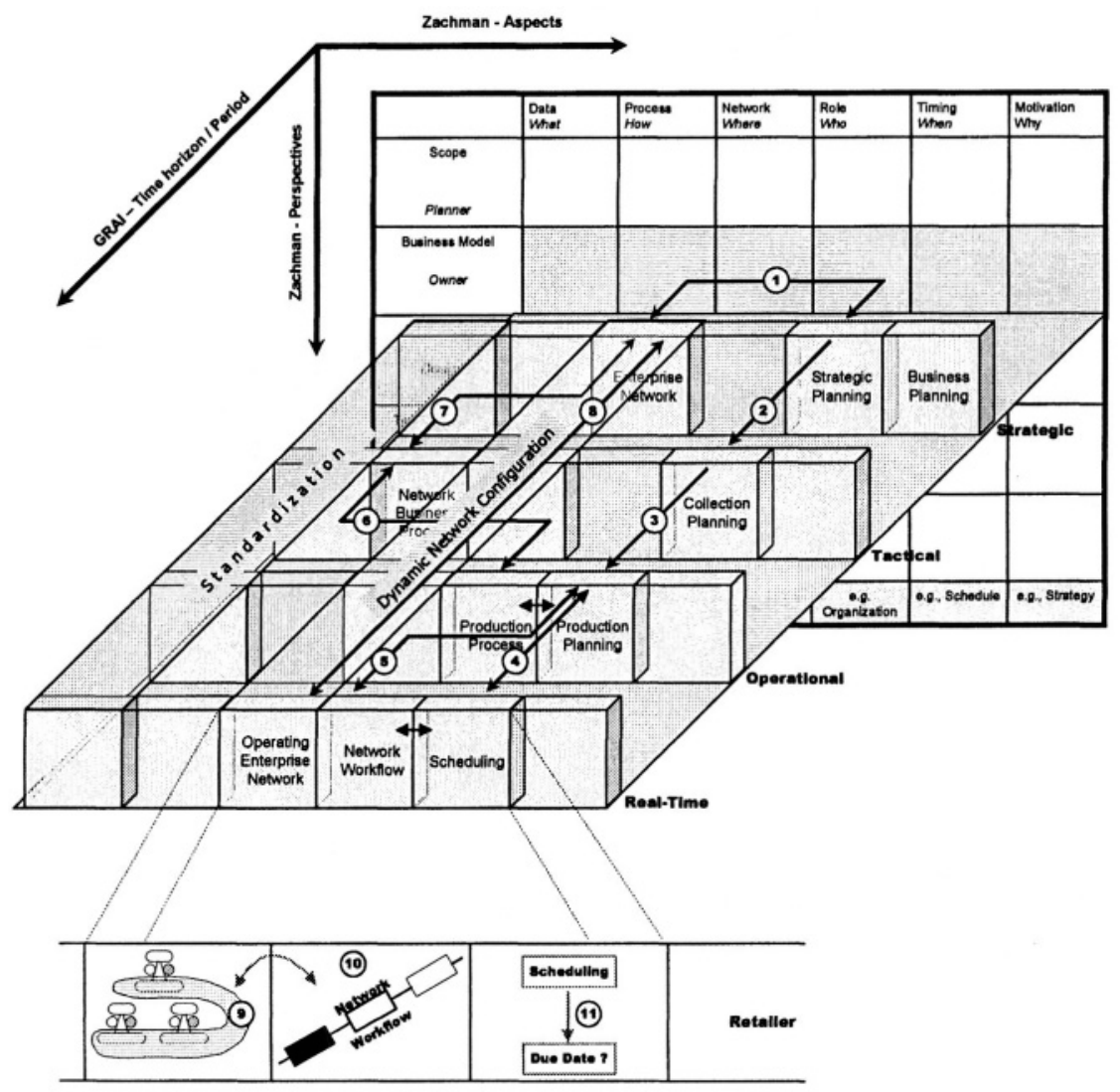

Figure 5 - Time horizon analysis, case study

- Tactical: At the tactical level one is already dealing the implementation of the business model. In the MyFashion.eu model, collection planning and design is the first phase of the implementation. At this horizon the network structure is further refined to accommodate the collection particular requirements. As a 
result of this tactical role we again have interaction with upper and lower decision levels: arrow 7 pictures the dependence that exists between the network business processes to be modeled and the strategic decisions made for identifying the involved business partners; on the other end, arrow 6 pictures the instantiation of network business processes into order fulfillment processes (e.g. production process) in both network and individual enterprises; at last, arrow 3 comprises the collection planning definition as a decisional framework to production planning.

- Operational: at the operational level we have the typical production planning activity with clear interaction with the real-time activities.

- $\quad$ Real-time: the operating enterprise network happens at "real-time", namely at the point in time where we have the interaction with the end-consumer at the point of sales (Retailer). In this context, we picture the instantiated business process as an executing workflow (10) that starts at the retail shop with the taking of the client measurements for a made-to-measure suit. As soon as this task is completed, a due date negotiation starts involving the suit manufacturer and the fabric supplier (4 and 5), which means that the whole supply chain is involved (9).

- Standardization: Standardization is a mean to reach an end. It's valuable at a high level where it encourages the following goals: Reuse of Existing Assets; Integration of Efforts; Interoperability; Interchangeable Infrastructure. Industry specific standardization is specially effective in this type of networks.

\section{CONCLUSION}

The Zachman Framework for Enterprise Architecture is currently assembled as a matrix cross-combining enterprise aspects and perspectives. Having in mind the inner value of this framework, this paper explored the introduction of the time perspective into the framework. To this end, the authors proposed a Zachman / GRAI-grid conceptual integration for the analysis of the business model of a network of enterprises, which was illustrated with a case study in the apparel industry.

This type of analysis can be further extended to cover all other aspects of the network enterprise (the six aspects of the Zachman Framework). The authors believe this approach can be particularly useful when dealing with enterprise networks with cyclical business models, as is the case of the apparel industry where the network itself is organized and managed according to some well defined time horizons.

\section{REFERENCES}

1. O'Rourke, Carol, et al. "Enterprise Architecture Using the Zachman Framework". Boston: Course Technology, 2003

2. Bernus P., Uppington G. "An Co-ordination of management activities - mapping organisational structure to the decision structure". In Coordination Technology for Collaborative Application Organizations, Processes, and Agents, W.Conen and G.Neumann (Eds), LNCS 1364, Springer Verlag, Berlin pp25-38, 1998 
3. Noran O. "An analysis of the Zachman framework for enterprise architecture from the GERAM perspective". Annual Reviews in Control 27 (2003) 163-183

4. Mintzberg H., "The rise and fall of strategic planning", The Free Press, London, 1994

5. Bernus, Peter et al; "Architectures for Enterprise Integration", London, Chapman \& Hall; 1996

6. Schiegg, Philipp. Garg, Amit. Roesgen, Robert. Toscano, César. Pinto Ferreira, J.J. Rabelo, Ricardo J. Klen, Alexandra Pereira. "Configuring Consumer-Demand Driven Supply Networks - in Made-toFit Fashion Sector". 2nd Interdisciplinary World Congress on Mass Customization and Personalization (MCP). Editors Prof. Dr. h.c. Ralf Reichwald, Prof. Mitchell M. Tseng, Dr. Frank Piller, 2003

7. MyFashion.eu. Organizational Reference Handbook for MyFashion.eu Supply Network Operations, Deliverable D8 MyFashion.eu (IST-2001-32560), 2003 